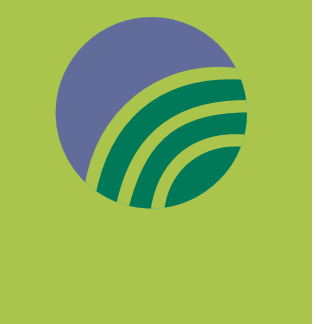

\section{Preview: 2017 Materials Research Society Fall Meeting \& Exhibit}

\author{
Hynes Convention Center and Sheraton Boston Hotel, Boston, Massachusetts \\ Meeting: November 26-December 1, 2017 Exhibit: November 28-30
}

www.mrs.org/fall2017
$\mathrm{T}$ he Materials Research Society (MRS) will hold its 2017 MRS Fall Meeting at the Hynes Convention Center and the Sheraton Boston Hotel in Boston, Mass., November 26-December 1. The Meeting will include technical programming, tutorials, an award ceremony, poster sessions, career fair, and other special activities.

MRS Meetings focus on interdisciplinary materials research worldwide. Symposium organizers from around the world have created a technical program of 54 symposia that address leadingedge research and capture the progress in materials science and technology. The symposia are organized into the following seven clusters.

\section{Symposium clusters}

The Biomaterials and Soft Materials cluster includes 12 symposia that cover a diverse range of topics, including bioinspired materials, 2D nanomaterials in health care, and biomaterials for regenerative engineering. The $2 \mathrm{D}$ nanomaterials area will include electronic materials and devices; nanosensors in clinical applications; biosensors in clinical applications; nanomaterials as a sensor platform; biomarker sensing; carbon-based nanomaterials in clinical applications; point-of-care devices for medical applications; and specialized sensors for pediatric, cardiology, and other diseases.

The Electronics, Magnetics, and Photonics symposia cover a broad range of advanced materials in electronic and photonic devices and their applications. Ten symposia will cover organic semiconductors, multiferroics and magnetoelectrics, oxide interfaces, diamond electronics, sensors and biotechnology, electronic and ionic dynamics at solidliquid interfaces, and other materials.

The Energy and Sustainability cluster will focus on perovskite materials and devices, a circular materials economy, sustainable solar fuels, energy storage, nuclear materials, and silicon for photovoltaics.

The Nanomaterials symposia include carbon quantum dots, anisotropic carbon nanomaterials, functional 1D nanostructures, 2D noncarbon materials and systems, and nanostructure-based optical bioprobes.

The Processing and Manufacturing cluster has roots in materials science, where processing is an essential component. The focus lies in the use of ion beams and plasmas in manufacturing, the importance of modeling in the manufacturing process, the development of sensor technology for environmental modeling, and roll-to-roll manufacturing to achieve hybrid and hierarchical structures in device applications.

The Theory, Characterization, and Modeling symposia cover multifunctional and multifrequency scanning probe microscopy, ion-beam technology and applications, mechanical behavior at the micro- and nanoscale, and design, control, and advanced characterization of functional defects in materials.

The Broader Impact cluster includes two symposia regarding materials science education partnerships and materials innovation in sustainable agriculture and industry. A panel discussion will focus

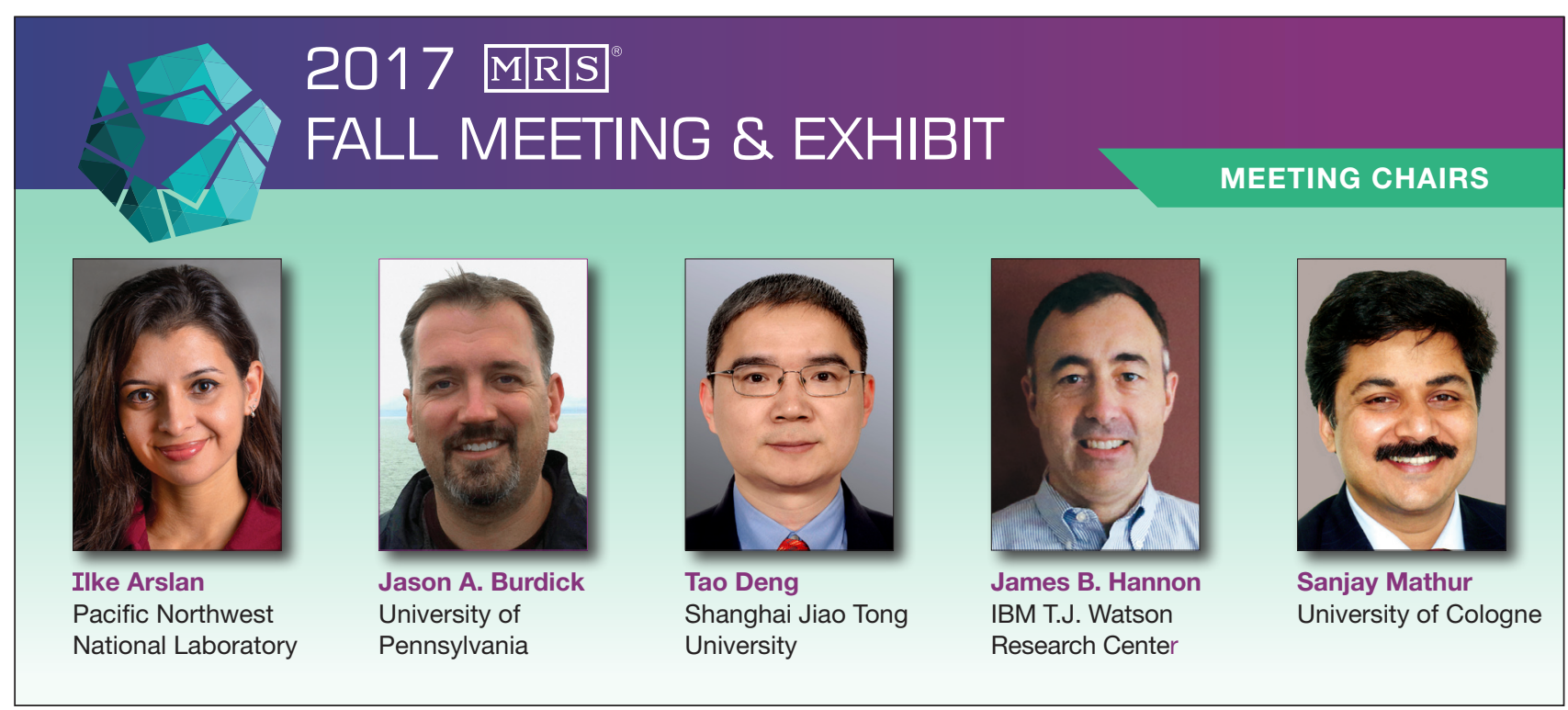


on effective partnerships between community college/university/business for a seamless transition of students from lower division programs into upper division degree programs and workforce.

To complement these sessions, 11 tutorials will be offered covering a variety of topics. All tutorial sessions will be held on Sunday, November 26.

\section{Plenary session and awards}

The Plenary Session Featuring The Fred Kavli Distinguished Lectureship in Materials Science presentation will be held on Monday, November 27, at 6:30 pm, in the Sheraton Boston Hotel, Grand Ballroom. This year's plenary speaker, James A. Warren, is the Director of the Materials Genome Program in the Material Measurement Laboratory at the National Institute of Standards and Technology (NIST). NIST has framed its support for the Materials Genome Initiative around the need for a data infrastructure that enables the rapid discovery of existing data and models, the tools to assess and improve the quality of those data, and the development of new methods and metrologies based on those data.

The Awards Ceremony will convene on Wednesday, November 29, at 6:30 $\mathrm{pm}$, in the Sheraton Grand Ballroom. The David Turnbull Lectureship, MRS Medal, Materials Theory Award, MRS Postdoctoral Awards, The Kavli Foundation Early Career Lectureship in Materials Science, Graduate Student Gold and Silver Awards, the Arthur Nowick Graduate Student Award, and Von Hippel Award will be presented. The inaugural MRS Bulletin Postdoctoral Publication Prize will be presented during the ceremony. For up-to-date award recipient information, please visit www. mrs.org/fall2017.

\section{Special sessions and events}

Throughout the Meeting week, a range of events and activities will honor Mildred "Millie" Dresselhaus, the "Queen of Carbon," pioneer of nanoscience and longtime member of MRS. Featured on Monday is the daylong Special Workshop on Nanomaterials and Their Applications - In Honor of Professor

\section{TUTORIALS}

The 2017 MRS Fall Meeting will feature 11 tutorials covering a variety of topics to complement the symposium sessions.

All tutorial sessions will be held on Sunday, November 26.

Tutorials are free of charge for all registered attendees. Tutorial notes will be available for purchase at the preregistration price of $\$ 35$. After the preregistration period ends, notes will be available for purchase for $\$ 45$ on-site.

Visit www.mrs.org/fall-2017-tutorial-sessions for locations and tutorial information. BM06 Future Perspective of 3D Graphene and Beyond
8:30 am - 12:00 pm

EM02 Magnetic and Magnetoelectric Materials for Memory and Sensing Applications $1: 30 \mathrm{pm}-5: 00 \mathrm{pm}$

EM08 Materials Science of Quantum Computing $1: 30 \mathrm{pm}-5: 00 \mathrm{pm}$

ESO4 Grid-Scale Energy Storage Materials and Systems $1: 30 \mathrm{pm}-5: 00 \mathrm{pm}$

ES05 Energy Storage System Materials and Design Safety Considerations - A Materials Perspective $1: 30 \mathrm{pm}-5: 00 \mathrm{pm}$

ES07 Scattering Methods for the Characterization of Materials 8:30 am - 5:00 pm

ES10 Sustainable Development of Materials $8: 30 \mathrm{am}-5: 00 \mathrm{pm}$

ES11 High-Efficiency Crystalline Silicon Photovoltaics: Fabrication, Devices and Testing 1:30 pm - 5:00 pm

TCO1/ Advanced Imaging and Spectral Data Analysis via Multivariate Statistical Methods

TCO3 8:30 am - 5:00 pm

TC02 In Situ Studies of Materials Transformations (TEM and X-Ray) 1:30 pm - 5:00 pm

TCO4 Long Timescale Atomic Simulations in Materials Science 8:30 am - 5:00 pm

\section{WWW.MRS.ORG/FALL-2017-TUTORIAL-SESSIONS}

Millie Dresselhaus for her life-long contribution and impact to materials research.

Symposium $\mathbf{X}$ talks provide Meeting attendees with an overview of leadingedge topics. Margaret Murnane, University of Colorado Boulder, will present "Capturing Nanoscale Materials Properties Using Tabletop Coherent Soft X-Ray Beams" on Monday, November 27; Younan Xia, Georgia Institute of Technology, will present "Toward Affordable and Sustainable Use of 
Noble-Metal Nanocrystals in Catalysis and Nanomedicine" on Tuesday, November 28; Jennifer A. Lewis, Harvard University, will address "Printing Soft Matter in Three Dimensions" on Wednesday, November 29; and Nam-Gyu Park, Sungkyunkwan University, South Korea, will discuss "History, Progress, and Perspective of Halide Perovskite Photovoltaics" on Thursday, November 30. All talks will take place from $12: 15$ to $1: 15 \mathrm{pm}$ at the Sheraton Boston Hotel.

Poster sessions, an integral feature of MRS Meetings, will be held in the evenings. The Meeting chairs will award

prizes of up to $\$ 500$ for the best posters during each evening session.

The Focus on Sustainability program will run seminars on incorporating sustainability into research in a comprehensive way, while considering real-world applications of these principles to product design and manufacture. The seminars are aimed at materials researchers at all career stages, from students to postdocs to faculty and industry researchers. There will also be a panel discussion "Materials Needs for Energy Sustainability by 2050: The Role of the Circular Economy" on Thursday, November 28, at 7:00 pm.

\section{HOTELS IN BOSTON}

MRS receives meeting space at a greatly discounted rate as a result of contracting a large block of sleeping rooms at the official meeting hotels. In order to keep meeting costs as low as possible and minimize the financial risk to MRS, we encourage you to utilize official MRS housing while you are attending an MRS meeting. Hotels offering discounted rates for the 2017 MRS Fall Meeting are listed below. To make reservations, visit www.mrs.org/fall-2017-hotels.

- Sheraton Boston Hotel Deadline: November 5, 2017 39 Dalton St., Boston, MA 02199 617.236 .2000 or 888.627 .7054 Group Rate: \$203/single; \$213/double; $\$ 20 /$ each additional person. ${ }^{*}$

- Boston Marriott Copley Place Deadline: November 1, 2017 110 Huntington Ave., Boston, MA 02116 617.236 .5800 Group rate: \$198 single; \$215 double; \$225/triple; \$235/quad.*

- Hilton Boston Back Bay Hotel Deadline: November 3, 2017 40 Dalton St., Boston, MA 02115 617.236.1100

Group Rate: \$210 single/double; $\$ 230$ triple/quad.* $^{*}$

- The Westin Copley Place Deadline: November 5, 2017 10 Huntington Ave., Boston, MA 02116 617.262 .9600 Group Rate: \$199/single; \$209/double; $\$ 20 /$ each additional person.*
- Boston Park Plaza Deadline: November 3, 2017 50 Park Plaza at Arlington St., Boston, MA 02116 617.426 .2000 or 800.225 .2008 Group Rate: \$175/single; \$175/double; \$195/triple; \$215/quad. *

- Embassy Suites Boston at Logan Airport Deadline: November 6, 2017 207 Porter St., Boston, MA 02128 617.567 .5000 Group Rate: \$159/single; $\$ 10 /$ each additional person. *

- The Colonnade Hotel Deadline: November 3, 2017 120 Huntington Ave., Boston, MA 02116 617.424 .7000

Group Rate: \$197/single; \$197/double; \$227/triple; \$257/quad.*

* plus applicable taxes and fees

Discounted room rates will be available until specified deadlines or until the group block is sold out, whichever comes first.
Throughout the week, Science in Videos (SciVid), a high-impact materials science video competition, will showcase finalists as they compete for recognition and prizes. Members will be asked to vote on their favorite videos from the SciVid competition finalists to determine the People's Choice winner. A viewing station and instructions will be located at the Public Outreach Center in the The Hub-Hall D, Level 2, Hynes Convention Center, and in several locations throughout the Meeting. The SciVid award ceremony will take place on The Hub Stage, Wednesday, November 29 at 4:30 pm. For more information, visit www. mrs.org/sci-vid.

An ABET (Accreditation Board for Engineering and Technology) Information and Evaluator Retraining Session will be offered to anyone who wants to learn more about the process, is preparing for an upcoming accreditation visit, or wants to ask questions about how to prepare a materials department for an accreditation visit. The training session will be held on Tuesday, November 28, from 7:15 to 9:30 pm, and can be attended without registering for the Meeting. Remote access will be available if unable to attend in person. New to this Meeting, there will be an ABET Information Booth. The MRS Accreditation Subcommittee and Charles Hickman, Chief Constituent Relations Officer at ABET, will host an informational discussion about the ABET accreditation program on Monday, November 27, from 5:30 to $6: 30 \mathrm{pm}$, on The Hub Stage, and are available for follow-up at the ABET Booth in the Exhibit Hall.

The National Science Foundation will provide speed coaching sessions for Meeting attendees at the Public Outreach Center on Tuesday, November 28 and Wednesday, November 29. The Division of Materials Research will be present to discuss funding opportunities, future program ideas, and sustainability.

iMatSci (Innovation in Materials Science) Innovator Showcase will be held Monday and Tuesday, November 27-28 in the The Hub. Each of the selected innovators will have space in The Hub. These finalists will present their technologies using various forms of media 
such as videos and prototypes. iMatSci is designed to showcase technologies that have not yet been productized, but where there is a working prototype or evidence of a repeatable process. The entities behind these innovations will generally be early stage and pre-revenue; however, iMatSci will also consider showcasing innovative technologies that are emerging from an existing corporate entity. Visit www.mrs. org/fall-2017-imatsci for more information.

The Women in Materials Science and Engineering Breakfast will be held on Wednesday, November 29, at 7:00 am. The guest speaker will be Linda Sapochak from the National Science Foundation.

Representatives from several government agencies will present overviews of Research Funding Opportunities on Tuesday, November 28 and Thursday, November 30 , at 5:30 pm. This event has been reformatted to allow MRS Meeting attendees the opportunity to meet directly with various program officers after an overview from each agency in a small group setting to allow for one-on-one interactions, questions, and comments.

The 2017 MRS Fall Meeting Career Fair will be held in The Hub, Tuesday and Wednesday, from 11:00 am to 5:00 pm. The Career Fair will provide an opportunity for Meeting participants and top employers to discuss career opportunities, and will feature recruiters and on-site interviews, career development sessions, and resume critiques and mock interviews. Students, postdocs, and seasoned professionals are all welcome.

The Research Mentor Training Workshop will be held on Sunday, November 26, from 1:00 to 4:00 pm, with a networking reception to follow, in the Sheraton Boston Hotel. Preregistration is required.

\begin{tabular}{|l|c|c|}
\hline \multicolumn{3}{|c|}{ REGISTRATION RATES } \\
\hline $\begin{array}{l}\text { 2017 MRS Fall Meeting registration includes a complimentary one-year } \\
\text { membership to MRS beginning January 1, 2018, through December 31, 2018.* }\end{array}$ \\
\hline & $\begin{array}{l}\text { PREREGISTRATION } \\
\text { before 5:00 pm (ET) } \\
\text { November 10, 2017 }\end{array}$ & $\begin{array}{c}\text { ON-SITE REGISTRATION } \\
\text { after 5:00 pm (ET) } \\
\text { November 10, 2017 }\end{array}$ \\
\hline Meeting Registration & $\$ 655$ & $\$ 795$ \\
\hline $\begin{array}{l}\text { Meeting Registration } \\
\text { with MRS Member Discount }\end{array}$ & $\$ 530$ & $\$ 660$ \\
\hline $\begin{array}{l}\text { Student Registration } \\
\text { Student Registration } \\
\text { with MRS Member Discount }\end{array}$ & $\$ 150$ & $\$ 145$ \\
\hline $\begin{array}{l}\text { Unemployed } \\
\text { Retired }\end{array}$ & $\$ 140$ & $\$ 170$ \\
\hline
\end{tabular}

* For a complete list of member benefits, visit www.mrs.org/membership.

The popular Science as Art competition will be held again at this Meeting. The competition is open to all registered Meeting attendees, with entries to be on display in the Exhibit Hall at the Hynes Convention Center. Multiple first-place and second-place awards of $\$ 400$ and $\$ 200$, respectively, will be presented. Guidelines and deadlines for entry will be available on the 2017 MRS Fall Meeting website.

A number of other events will take place throughout the Meeting, including professional development opportunities. To stay up to date with additional events and activities, access www.mrs. org/fall2017.

\section{For more information}

Registration for the 2017 MRS Fall Meeting includes a complimentary one-year membership to MRS beginning January 1, 2018, through December 31, 2018. The deadline to preregister for the Meeting is November 10, 2017, 5:00 pm (ET). International travelers are reminded to allow ample time to obtain a visa, if necessary. For additional details about the Meeting, contact MRS Member Services, Materials Research Society, 506 Keystone Drive, Warrendale, PA 15086-7573, USA; email info@mrs. org, tel. 724-779-3003, and fax 724779-8313. Details of various events and activities will be available via the MRS Meeting App and in the Program \& Exhibit Guide available on site. The MRS website can also be accessed for updated information on confirmed talks, details of special events, information on obtaining a visa, and for preregistration: www.mrs.org/fall2017.

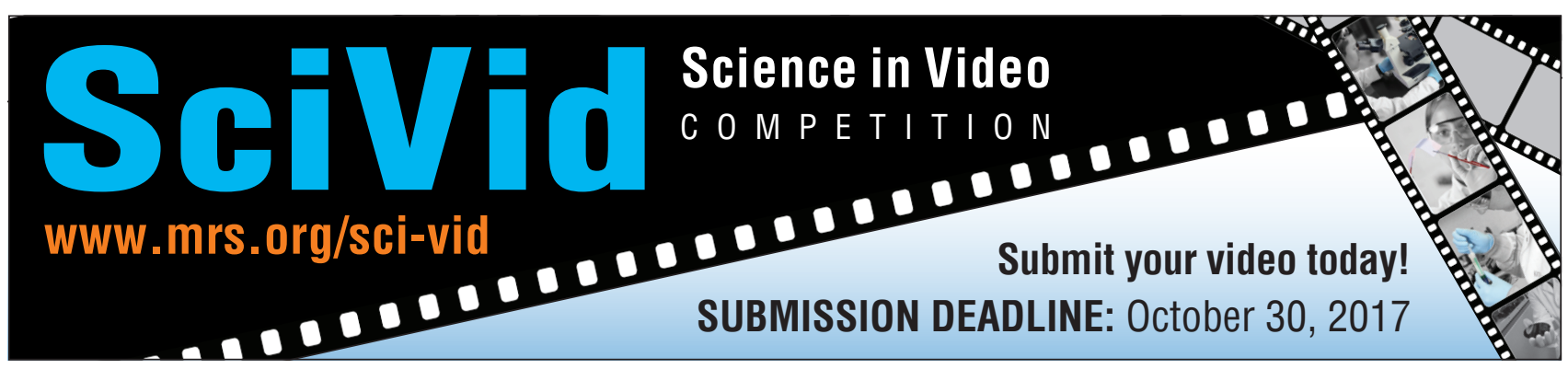




$$
\begin{aligned}
& \text { Tuesday, November } 28 \ldots \ldots \ldots \ldots \ldots . .11: 00 \mathrm{am}-5: 30 \mathrm{pm} \\
& \text { Wednesday, November } 29 \ldots \ldots \ldots \ldots . .11: 00 \mathrm{am}-5: 30 \mathrm{pm} \\
& \text { Thursday, November } 30 \ldots \ldots \ldots \ldots \ldots . .10: 00 \mathrm{am}-1: 30 \mathrm{pm}
\end{aligned}
$$

1-Material Inc

abcr GmbH

ABET

Across International

ACS Publications

Admiral Instruments

AdValue Technology, LLC

Advanced Polymer Materials Inc.

Advanced Research Systems, Inc.

Aerotech, Inc.

AIP Publishing

AJA International, Inc.

Alemnis AG

American Physical Society

Amuneal Manufacturing Corp.

Anasys Instruments

\section{ANCORP}

Andeen-Hagerling, Inc.

Anderson Dahlen Inc., Applied

Vacuum Division

Angstrom Engineering Inc.

Angstrom Sciences Inc.

Angstrom Scientific Inc.

Annealsys

Anton Paar USA

Applied Surface Technologies

Asahi Spectra Co., Ltd.

Asylum Research, an 0xford

Instruments Company

attocube systems Inc.

B\&W Tek

Barnett Technical Services

Bio-Logic USA, LLC

Biolin Scientific, Inc.

Blue Wave Semiconductors, Inc. BNNT, LLC

Brooks Automation, Inc.

Bruker

Bruker AFM Probes

Bruker Nano Surfaces

Cambridge Polymer Group, Inc.

Cambridge University Press/Materials Research Society

Chemat Scientific

Cornell University

CRAIC Technologies, Inc.

CRC Press, Taylor \& Francis Group

CrystalMaker Software Ltd.

CVD Equipment Corporation

DCA Instruments, Inc.

De Gruyter

Delong America Inc.

DigiM Solution LLC

Digital Surf

Direct Electron, LP

Dr. Fritsch FAST/SPS Systems and

Powder Shaping Technologies

Duniway Stockroom Corporation
Dutch Diamond Technologies BV

Ebara Technologies, Inc.

Ecopia Corp.

EDAX Inc., AMETEK Materials

Analysis Division

Edinburgh Instruments Ltd.

Edwards Vacuum

Electron Microscopy Sciences

Elsevier Ltd.

EmCrafts Co., Ltd.

Energetiq Technology, Inc.

Evactron ${ }^{\circledR}$ by XEI Scientific, Inc.

FemtoTools $A G$

Ferrotec (USA) Corporation

Film Sense

Filmetrics, Inc.

Fischione Instruments

Form-Tech Scientific Inc.

Fraunhofer USA Center for Coatings and Diamond Technologies

Furuya Metal Americas, Inc.

Gamry Instruments

Gatan

Geib Refining Corporation

Gencoa USA

Glines \& Rhodes, Inc.

GNB Corporation

Goodfellow Corporation

Heidelberg Instruments Inc.

Herzan LLC

Hitachi High Technologies America, Inc.

HORIBA Scientific

Hummingbird Scientific

Huntington Mechanical Laboratories, Inc.

HYPRES, Inc.

Image Metrology A/S

INFRA Technology

Integrated Dynamics Engineering

International Centre for Diffraction Data (ICDD)

Intlvac Thin Film

InVacuo, Inc.

ION-TOF USA, Inc.

Ionomr Innovations Inc

IOP Publishing

ISS, Inc.

J microTechnology, Inc.

Janis Research Company, LLC

Japan Science and Technology Agency

Japan Society of Applied Physics

JASCO

JEOL USA, Inc.

Kaufman \& Robinson, Inc.

Keysight Technologies

KLA-Tencor Corporation

Kleindiek Nanotechnik

KP Technology USA Inc.
Kurt J. Lesker Company

Lake Shore Cryotronics, Inc.

Leica Microsystems Inc.

Leybold USA Inc.

Linseis Inc.

M. Braun Inc.

MANTIS-SIGMA

Materion

McGraw-Hill Education

MDC Vacuum Products, LLC

MDPI AG

Metrohm USA, Inc.

Micro Materials Ltd

MICROCERTEC INC

MilliporeSigma (Sigma-Aldrich

Materials Science)

MKS Instruments

MMR Technologies, Inc.

Montana Instruments Corporation

MTI Corporation

Naieel Technology

Namiki Precision Jewel Co., Ltd.

NanoAndMore USA, Inc.

NanoMagnetics Instruments Ltd.

Nanomechanics, Inc.

Nanonics Imaging Ltd.

NanoScience Solutions

Nanoscribe GmbH

Nanosurf, Inc.

NANOVEA

National Reconnaissance Office

neaspec $\mathrm{GmbH}$

Neocera, LLC

NETZSCH Instruments North

America, LLC

Nor-Cal Products, Inc.

NT-MDT America, Inc.

Olympus America Inc.

OptiGrate Corporation

OriginLab Corporation

Ostec-ArtTool Ltd.

Oxford Instruments

Oxford University Press

PANalytical Inc.

Park Systems Inc.

Particle Sizing Systems, LLC

Pfeiffer Vacuum

Physics Today

PIEZOCONCEPT

Plasmaterials, Inc.

Princeton Scientific Corp.

PROTO

Protochips

PVD Products, Inc.

Quantachrome Instruments

Quantum Design, Inc.

R.D. Mathis Company
Radiant Technologies, Inc.

Raith America, Inc.

Reliable Corporation

Renishaw Inc.

RHK Technology, Inc.

Rigaku Americas

Royal Society of Chemistry

SAES Group

SAGE Publishing

Scienta Omicron, Inc.

Seki Diamond Systems

Semiconsoft, Inc.

Semilab

SmarAct Inc.

Solartron Analytical, AMETEK Advanced

Measurement Technology

Solid State Cooling Systems, Inc.

SPECS Surface Nano Analysis, Inc.

SPEX SamplePrep LLC

SPI Supplies, a Division of Structure

Probe, Inc.

Springer Nature

SPS-Europe B.V.

STAIB Instruments, Inc.

Strem Chemicals, Inc.

Super Conductor Materials, Inc

SVT Associates, Inc.

Synton-MDP AG

TA Instruments

TDC Corporation

Tecuum AG

Ted Pella, Inc.

Telemark

Tescan USA Inc.

Thermo-Calc Software Inc.

Thermo Fisher Scientific

THINKY USA, Inc.

TMC, AMETEK Ultra Precision

Technologies

Toho Technology Inc.

Toshima Manufacturing Co., Ltd.

TREK, INC.

Trion Technology, Inc.

UC Components Inc.

ULVAC Technologies, Inc.

Vacuum Technology Inc.

VAT Group

Vigor Tech USA

Wafer World Inc.

Wiley

WITec Instruments Corp.

J.A. Woollam Company, Inc.

ZEISS Microscopy

Zurich Instruments Ltd.

Zygo Corporation, AMETEK Ultra

Precision Technologies 